\title{
'N BRIEF VAN STROOI?: DIE EVANGELIE IN JAKOBUS
}

Jakobus is ' $n$ juweel. Dit is so jammer dat Luther die brief 'n slegte naam gegee het deur dit "eyn rechte stroern Epistel ..." te noem, omdat dit, volgens hom, geen evangeliese inslag het nie ("den sie doch keyn Euangelisch art an yhr hat." ${ }^{\prime \prime}$ So is dit as't ware 'geëtiketteer' en die naam het bly kleef. Die meeste ondersoeke van die brief begin met die vermelding van Luther se uitspraak en probeer vanaf hierdie punt om die vaandel vir die brief te swaai, hetsy op Protestantse hetsy op RoomsKatolieke wyse. Dit is jammer! Hierdie artikel beoog om deur middel van 'n paar algemene inleidende opmerkinge die leser te nooi om die brief weer ' $n$ slag ter hand te neem en te deel aan die geestelike skatte wat dit aanbied en om dan die een aspek wat al te dikwels by Jakobus skeef voorgestel word in fyner besonderhede uit te werk.

\section{Inleiding}

Hoe langer ' $n$ mens by die Jakobusbrief vertoef, hoe meer gryp dit jou aan: die gesag van die skrywer, die oorredende trant van sy redevoering, die aard van die inhoud, gewortel in die Ou-Testamentiese en Joodse tradisie soos dit veral neerslag gevind het in die wysheidsliteratuur maar nuut geinterpreteer is deur 'n christenskrywer wat oorvloedig put uit die leer van Jesus. Vanuit hierdie agtergrond sê Jakobus met min woorde so oneindig baie.

Die taalkenner vind in die brief die beste Grieks van die Nuwe Testament, uitgesonder miskien die Hebreërbrief. Terselfdertyd het die skrywer sy Joodse idioom op voortreflike wyse gehandhaaf sodat ons 'n letterkundige produk kry wat die taalkenner uittart om elke uitdrukking na reg te waardeer. Die skrywer beskik oor ' $n$ besondere stylvaardigheid en dit gee aan die brief ' $n$ skerp indiwiduele profiel. Een van die groot raaisels van die boek is juis dat ' $n$ Joodse skrywer sulke goeie Grieks op só 'n wyse kon hanteer.

Hierdie skrywer was niemand anders as Jakobus, die broer van Jesus nie. Dit is die oortuiging waartoe mens kom nadat alle beskikbare gegewens opgeweeg is. Tydens sy aardse bestaan, het Jakobus nie in Jesus geglo nie; trouens, die klanke wat in Johannes deurslaan, verraai 'n vyandige gees van die kant van Jesus se broers teenoor Hom (Joh 7:1-7). Jesus het egter na sy opstanding aan Jakobus verskyn $(1 \mathrm{Kor}$ 
15:7). Wat daar tussen hulle gebeur het is 'n geheim, waarvan iets deurskemer in Jakobus se brief. Gemeet aan die lengte van die brief, is daar meer verwysings na en toespelings op die leer van Jesus as in enige ander Nuwe Testamentiese geskrif. ${ }^{2)}$

Hierdie algemene stellings is bedoel om die 'strooi' so 'n bietjie weg te krap van die oppervlakte van die brief om aan die leser net ' $n$ paar juwele te toon; een waarvan ons in die hand gaan neem om van nader te bekyk. Dit kan miskien ' $n$ bydrae lewer dat meer uit Jakobus gepreek sal word en dit op ' $n$ werklik 'evangeliese' wyse, want die brief is nie wettisisties van aard nie.

\section{Die skrywer se hantering van die indikatief-imperatief}

Dat die brief sterk 'imperativies' van aard is, kan niemand ontken nie. Van die 108 verse word 54 op imperatiewe wyse uitgespreek. Dit word nog beklemtoon deur die gesagstoon van die skrywer en die aandrang op die daad.

\subsection{Die imperatiewe karakter van die brief}

Die hele brief kan gekarakteriseer word as ' $n$ aandrang om die werke van 'die wet' uit te leef (2:14-26). Hierdie waarheid dryf hy op 'n spits in sy betoog oor die nutteloosheid van die geloof sonder werke en dit is voorwaar 'n skerp spits wat hy teken: "Julie sien dus dat die mens geregverdig word op grond van sy dade en nie net op grond van sy geloof nie." In die teologie word hierdie aspek beklemtoon omdat dit nie alleen die Paulus-Jakobusdiskussie aan die gang hou nie, maar ook omdat dit apologeties aangewend word om Protestantse en Rooms-Katolieke aksente te regverdig. Luther se evaluering, soos in die begin genoem, word deur albei groepe as hefboom gebruik en op dié wyse kry ons te doen met 'n verwronge beeld van een van die pragtigste werke in die Nuwe Testament. Dit is sterk te betwyfel of die skrywer die perikoop oor geloof sonder werke $(2: 14-26)$, as die middelpunt van sy werk bedoel het. $^{31}$

\subsection{Die sentrale tema: 'volkomenheid'}

Sy sentrale tema vir die hele brief stel hy reg aan die begin van die brief: "My broers, julle moet baie bly wees wanneer allerlei beproewings oor julle kom, want, soos julle weet, as julle geloof die toets deurstaan het, stel dit julle instaat om te volhard. En die volharding moet enduit volgehou word sodat julle tot volle geestelike rypheid kan kom, sonder 
enige tekortkoming" (hina ete teleioi kai holokleroi, en medeni leipomenoil. $\mathrm{Na}$ alle waarskynlikheid sluit die skrywer hierin aan by die leer van die Here Jesus in die bergrede oor die uitlewing van liefde: "Wees julle dan volmaak soos julle hemelse Vader volmaak is." (Matt $5: 48$ ). Sy groot hartstog is om sy lesers tot volle geestelike rypheid te lei en in die slotverse van die brief stel hy aan hulle dieselfde doel voor oë om die afgedwaalde terug te bring. Die trefwoord is elke keer, om 'nie af te dwaal nie' $(1: 16 ; 5: 19,20)$. So 'n konstruksie aan die begin en die einde van ' $n$ Skrifdeel, is nie alleen ' $n$ vorm van beklemtoning nie, maar wil ook die ingeslote geheel betekenis gee. Dit is tewens een van die uitstaande kenmerke van die brief dat die skrywer alles wat die volle geestelike rypheid van die gelowige in die weg kan staan, onverbiddelik veroordeel en aan die anderkant, die weg aanwys wat kan lei tot geestelike wasdom. Die wyse waarop hy dit doen, kan nie anders as om inslag te vind nie. Hy spreek met 'n dwingende gesag en oorredende aandrang: "My liewe broers. dit moet julle in gedagte hou ..." (1:19); "Wat help dit, my broers, as iemand beweer dat hy glo, maar sy dade bevestig dit nie?" (2:14); "En nou, julle rykaards, kerm en kla ..." (5:1); "Weet julle nie, julle ontroues (letterlik: julle hoereerders), dat vriendskap met die wêreld vyandskap teen God is nie?"' (4:4). So klink dit dwarsdeur die brief.

Nog 'n metode wat hy gebruik om skerpte te verleen aan sy aandrang tot die daad, is kontras: God wat so 'heelhartig' sonder voorbehoud en sonder verwyt (hap/ōs) gee (1:5), en die dubbelslagtige mens (dipsuchos) wat twyfel $(1: 6,7)$; die tong wat God loof en terselfdertyd die mens kan vloek (3:9); die gemeente wat witvoetjie soek by die rykes en die armes minag (2:1v); aardse, duiwelse wysheid teenoor die wysheid van Bo (3:13-18) - om maar 'n paar voorbeelde te noem. Dit is opmerklik dat Jesus ook sy uitspraak in Matt 5:48: "Wees julle dan volmaak soos julle hemelse Vader volmaak is", opvolg deur daarop te wys hoe dubbelhartig die mens is. As hy die armes help, dan doen hy dit om deur God én mens gesien te word (Matt 6:1-4); as hy bid, doen hy dit om deur God én mens gehoor te word (Matt 6:5-6) - so ook as hy vas (Matt 6:16). Jesus dring daarop aan dat die mens (se oog) haplous, d.i. 'een-motiewig' sal wees (Matt 6:22), want hy kan nie twee here dien nie (Matt 6:14).

\subsection{Die Christologiese voorveronderstelling}

Jakobus plaas inderdaad 'n swaar aksent op die regte lewe; of om dit anders te stel, op die imperatief. Wat van die indikatief - die werk van God in Christus om die gelowige in staat te stel om te kan lewe volgens sy 
wil? Die oppervlakkige indruk is dat Jakobus aan hierdie aspek nie reg laat geskied nie, of dit tenminste onderbeklemtoon. Die naam "Here Jesus Christus" kom net tweemaal in die hele brief voor, 1:1 en 2:1.

Dit het sommige geleerdes laat beweer dat Jakobus eintlik ' $n$ voorchristelike Joodse geskrif is wat verchristelik is deur die invoeging van die Naam, Here Jesus Christus. Hierdie standpunt word nie meer aanvaar nie omdat die verchristeliking van die brief op so ' $n$ wyse nie gehandhaaf kan word nie. Die hele brief berus op christelike voorveronderstellings soos blyk uit die verwysing na die ouderlinge van die "gemeente" (tès ekk/esias), die "eerstelinge" (aparchèn) wat gered is deur die Woord (1:18), sy goeie Naam wat uitgeroep is oor die gelowiges (2:7) as toespeling op die doop en sy wederkoms $(5: 7,8,9)$ - om maar 'n paar voorbeelde te noem. Die wedergeboorte, doop en wederkoms veronderstel sy kruis, opstanding en hemelvaart. Ten tye van die skrywe van hierdie brief het die paasgebeure as't ware "nog in die lug gehang."

Hierdie waarheid word onderstreep deur die wyse waarop die naam "Here Jesus Christus" in 1:1 en 2:1 gebruik word. As Jakobus homself "dienaar van God en die Here Jesus Christus" noem, dan dui die naam "Here" op Jesus Christus as die Een wat die heerskappy aanvaar het, d.i. die verhoogde Heer aan die regterhand van God. Dit het Hy geword op grond van sy sterwe en opstanding. Die briefaanhef adem dus reeds die gees van die eerste christelike belydenis: Jesus is Here (kurios). In 2:2 brei die skrywer hierop uit. Hy sê: "My broers, julle wat glo in ons Here Jesus Christus, die Here van die heerlikheid, moet mense nie volgens hulle uiterlike beoordeel nie." (NAV) Dit is die beste betekenisweergawe van 'n uiters moeilik vertaalbare Griekse konstruksie: Adelphoi mou, me en prosopolèmpsia echete tèn pistin tou kuriou hemon lesou Christou tes doxēs. Sonder om die aangehaalde vertaling te beredeneer, moet daarop gewys word dat die hele gedeelte van tou kuriou tot by tes doxes in die genitief staan. Die vraag is watter woord die uitdrukking "van heerlikheid" (tès doxēs) kwalifiseer? Die wyse waarop die woordorde in die Grieks hierbo geplaas word, lê klem op "ons Here" en op "van heerlikheid" - die begin en einde van die uitdrukking - en dit ondersteun die vertaling. Só verstaan, word die verheerliking van Jesus as Here, bedoel. Met ander woorde, die skrywer verwys na Hom as die een wat aan die kruis gesterf het, opgestaan het en opgevaar het na die hemel; weer eens 'n beklemtoning van die paasgebeure. Die skrywer sê baie dinge so kort en dan bedoel hy dat voile betekenis daaraan geheg sal word. Hiermee is genoegsaam aangetoon dat die inhoud van die brief gefundeer is op die genadewerk van God in die Here Jesus Christus. Van die gelowige word vereis om te antwoord op hierdie genadewerk van God. 


\subsection{Woord en wet}

Die antwoord wat die gelowige moet gee op die genadewerk van God verwoord Jakobus met die wet tot naasteliefde wat hy uit Lev 19:18 aanhaal. Soos vir Paulus (Rom 13:9) is dit vir hom die samevatting van die hele wet, want al die verskillende gebooie plaas die mens voor die een Wetgewer $(2: 10,11 ; 4: 12)$. 'n Lewe volgens hierdie wet is vir hom 'n lewe wat tot volle geestelike rypheid gekom het, egte en suiwer godsdiens $(1: 27)$ wat nie volgens die uiterlike oordeel nie $(2: 1-4)$ en wat bewys lewer van egte geloof $(2: 14-26)$.

Om egter van die wet by Jakobus te praat sonder om dit in verband te bring met die evangelie, is om hom ' $n$ onreg aan te doen. In 1:18 word in skeppingstaal van die onveranderlikheid van God gepraat. Op grond van sy vrymagtige wil het Hy "ons" herskep of tot lewe gebring (hèmas apekuesen) deur sy Woord van waarheid (logo aletheias) om eerstelinge te wees van sy skepping. Logó is ' $n$ dativus instrumentalis en verwys na die wederbarende werking van die evangelie. In 1:21 word die gedagtegang verder ontwikkel met die begrip "ingeplante Woord wat kan red" (ton emphuton logon ton dunamenon sosai) waaraan die gelowige in sagmoedigheid moet vashou. Volgens 1:18 bewerk hierdie Woord die wedergeboorte en dit word in verband gebring met "elke goeie gawe en elke volmaakte geskenk" wat "van Bo kom." In 1:21 het ons dus weer duidelik ' $n$ toespeling op die evangelie wat iemand aangeneem het tot redding en waaraan hy gelowig moet vashou. Dit herinner aan Jesus se uitsprake in Johannes: die nuwe geboorte kom van Bo (Joh 3:3); "As julle aan my woorde getrou bly (in my woorde bly), is julle waarlik my dissipels; en julle sal die waarheid ken, en die waarheid sal julle vry maak" (Joh 8:31), en van God se Woord wat werklik in iemand lewe (Joh 5:39).

Die skrywer se uiteensetting oor die werking van die Woord, bring hom by die eintlike punt wat hy wil maak: "Julle moet doen wat die Woord sê" (1:22). Maar nou tree daar 'n uiters interessante wending in woordgebruik in. Die een wat doen wat die Woord sê, word beskryf as "iemand wat hom verdiep in die volmaakte wet wat ' $n$ mens vry maak, en hom daaraan hou" (ho paraskupsas eis nomon teleion ton tès e/eutherias kai parameinas). In 1:21 en 1:25 het ons dus te doen met ongeveer semantiese parallelle. Ingeplante Woord word egter nou vervang met volmaakte wet van vryheid. Die vraag ontstaan nou of Woord en wet vir die skrywer volkome sinonieme begrippe is. Hy het Woord immers met wet vervang: die Woord wat kan red, met die wet wat vry maak. Die verband sê, nee. Die Woord van waarheid wat die wedergeboorte werk, is die evangelie en dit is tegelyk die ingeplante Woord. Die 
vashou aan hierdie Woord het baie bepaald ook sedelike implikasies, maar ' $n$ mens sou nie dieselfde van die wet kan sê as wat jy van die Woord kan sê nie. Jy sou nie van die wet kan sê dat dit die mens wederbaar nie. Wanneer nomos egter logos in semantiese parallelisme vervang, in die aandrang van die skrywer om te doen wat die Woord sê, wil dit aandui dat die wet die realisering is van die evangelie. Om dit nog anders te sê: logos en nomos staan in verband met mekaar soos die binnekant en die buitekant van dieselfde saak. Dit funksioneer as integrale eenheid - die imperatief as keersy van die indikatief.

\subsection{Die volkome wet van die vryheid}

Die woordorde in nomon teleion ton tes eleutherias laat die klem op die kwalifiserende woorde val, wat hierdie wet duidelik wil onderskei van 'n wet wat nie volkome is nie en wat nie kan vry maak nie. Op hierdie wyse repudieer die skrywer die Joodse wetsbeskouing wat die verantwoordelikheid voor God wou systap deur'n beroep op die nakoming van die afsonderlike wette van die dekaloog. Sy hele betoog in $2: 8-13$ is hierop toegespits. Die afsonderlike wette van die dekaloog stel die gelowige voor die Wetgewer: Hy "wat gesê het." Dieselfde waarheid beklemtoon hy ook in 4:11-12. Dit is 'n volkome wet omdat dit die mens geheel en al (met sy hele hart, sy hele siel, sy hele verstand en al sy kragte, Mark 12:29) opeis vir God en sy naaste. Dit is 'n wet wat vrymaak omdat die ingeplante Woord die mens op grond van die werk van Christus herskep tot ' $n$ nuwe gesindheid van gehoorsaamheid en liefde as die bestaansgrond van die koninkryk. Daarom word dit in 2:8 die "wet van die koninkryk" (nomon basilikon) genoem. Die volkomenheidsmotief waarmee die brief begin het (hina ete teleioi kai holokleroi, en medeni leipomenoi, 1:4) word dus deurgetrek na gehoorsaamheid en die uitlewing van die wet van naasteliefde. ' $n$ Lewe volgens hierdie wet. (die nomon teleion) is ' $n$ lewe in die rigting van teleios. Hoe evangelie en wet in die hele verband saamhang, word geillustreer deur 'n voorbeeld te noem van die oortreding van die wet van die naasteliefde in die voorkeurbehandeling wat die gemeente die ryke laat toekom ten koste van die arme en dan te sê dat so 'n optrede nie te rym is met "die geloof in die Here Jesus Christus, die Here van die heerlikheid" nie (2:1).

\subsection{Geloof en werke}

As verlengstuk en sluitsteen van die skrywer se denke oor die eenheid van Woord en wet of indikatief en imperatief, dien sy betoog oor die eenheid van geloof en werke in die regverdiging van die mens. Die probleem 
word benader vanuit die verhouding tot die naaste soos blyk uit 2:15-17 en omdat dit van wesentlike belang is vir die hele onderwerp, sal dit eksegeties in fyner detail behandel word. Die gedeelte 2:14-26 handel oor die tema geloof sonder werke is dood en verdeel in drie onderafdelings: a) 2:14-17 - die sentrale tema toegelig met ' $n$ voorbeeid en afgesluit met ' $n$ konk/usie. b) 2:18-19 - die argument. c) 2:20-26 die Skrifbewys.

Elk van die onderafdelings a) en c) begin en eindig met dieselfde gedagte - as geloof nie deur werke gestaaf word nie, is dit dood. Dit is dus met ' $n$ ringskomposisie as eenhede opgebou. Die twee ringskomposisies omsluit die argumentgedeelte wat die sleutel tot die verstaan van die geheel bevat. Skematies kan dit soos volg voorgestel word:

Geloof sonder werke is dood $2: 14-16$

a. 2:14: $\quad \ldots$. geloof sonder werke kan nie red nie

2:17: $\quad \ldots$ geloof sonder werke, is dood $\ldots$.

b. 2:18: Maar iemand kan miskien sê $\ldots \ldots \ldots \ldots$ hulle sidder van angs. 
c. $2: 20: \quad \ldots$. geloof sonder werke, is nutteloos

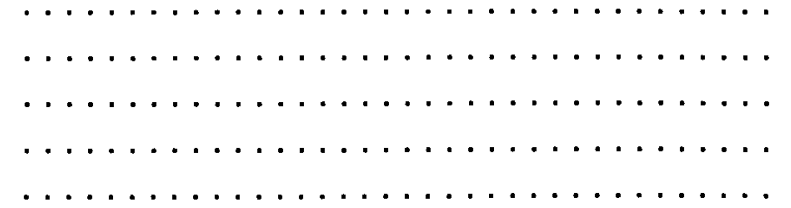

2:26: $\ldots$. geloof sonder werke, is dood.

Die sleutelbetekenis van die argument c) blyk uit sowel die oppervlakte struktuur as die styltegniek. Dit is aan die temagedeelte verbind met semanties ooreenstemmende inleidings:

14. pistin .... echein

(geloof ..... het)

14. erga ..... eche

(werke sou hê)
- 18. pistin .... echeis

- (geloof ..... het)

- 18. erga ..... echo

- (ek het werke)

en met die slotgedeelte deur die gelykluidende

choris ton ergon, $\vee 18$

en choris ton ergon, $\vee 20,26$.

(sonder die werke)

Die styltegniek van die skrywer is egter meer betekenisvol. In a) spreek hy die leser direk aan en laasgenoemde word betrek deur hom self aan die woord te stel. In b) gebruik die skrywer 'n soort van diatribestyl wat ook bekend was in die sinagogeprediking. Dit is ingestel op die oorreding van die leser tot die standpunt van die redenaar. Die leser word egter indirek benader deurdat ' $n$ denkbeeldige opponent geskep word met wie die skrywer ' $n$ dialoog voer. Die leser word ' $n$ toeskouer en hy weet by voorbaat dat die opponent nie met die skrywer saamstem nie. Die opponent se teenoorgestelde standpunt word gebruik as aanleiding vir die skrywer om sy gesigspunt te verduidelik en in te skerp. Intussen is die verwagting dat die toeskouer/leser saam met die skrywer standpunt sal inneem teenoor die opponent. Om hom te beïnvloed, word die opponent negatief gekarakteriseer. In hierdie geval is hy soos die duiwel en 'n dwaas.

Jakobus het tot die slotsom gekom dat geloof, as dit nie deur dade 
bevestig word nie, sonder meer dood is. Die opponent se argument is: "Die een het die geloof en die ander die dade." Met ander woorde, die twee kan afsonderlik voorkom.

So 'n moontlikheid wys Jakobus met skerpte en 'n argumentum ad absurdum af. 'n Blote verstandsgeloof soos die duiwels ook het is wel belangrik, maar nie genoegsaam vir redding in die oordeel nie. Die duiwels glo ook dat God Een is, maar hulle weet dat sodanige kennis hulle nie in die gerig kan red nie en dit is juis hierdie kennis wat hulle taat sidder van angs.

Die volgende Skrifbewys moet die saak nou finaal besleg. Abraham is by uitstek die geloofsvoorbeeld, maar in 2:21 word sy regverdiging deur God (edikaiōthe is 'n passivum divinum) gegrond op sy werke (ex ergon edikaiothe). In 2:23 bring die Skrifsitaat dit egter in verband met sy geloof. Tussen hierdie twee punte word dit duidelik hoe die skrywer die eenheid van geloof en werke bedoel:

V21 Abraam ho patēr hēmōn.

ex ergōn

(Abraham ons vader is uit werke geregverdig)

EDIKAIŌTHE

V22 Blepeis hoti

(Sien jy dat ...)
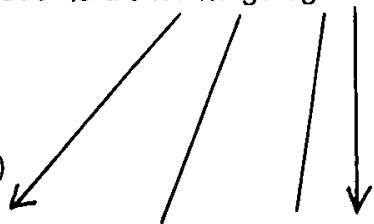

hē pistis sunergei

tois ergois autou

(die geloof gepaardgegaan het met die werke van hom)

$\downarrow \quad \downarrow$

kai ek tōn ergōn hē pistis ETELEIŌTHE

(en uit die werke het die geloof volkome geword)

V23 kai eplērōthē hē graphē ē legousa

(en die Skrif is vervul wat sê...)

episteusen de Abraam tō Theō

(en Abraham het in God geglo)

kai elogisthē autō eis DIKAIOSUNĒN

(en dit is vir hom gereken tot geregtigheid) 
Na blepeis hoti volg 'n parallelismus membrorum:

(die geloof het met die werke gepaard gegaan ... en die geloof het uit die werke volkome geword het), waarin die tweede lid semanties ongeveer sinoniem is aan die eerste. Die eerste lid van die parallel sê: die geloof het meegewerk met sy werke. Die bedoeling kan egter nie wees dat die werke daar was en dat dit telkens deur die geloof aangehelp is nie. So ' $n$ betekenis word deur die eerste sinsdeel uitgeskakel. Eerder word die geloofsingesteldheid as die konstante faktor gesien en dit het tot uiting gekom in die werke sodat die imperfektum sunergei hier die betekenis kry van begelei. Die geloof het met die werke gepaard gegaan. Hierdie bedoeling word duideliker weerspieël in die tweede sinsdeel: en die geloof het uit die werke volkome geword. Op hierdie wyse word die inherente eenheid van geloof en werke beklemtoon. Dit is nie moontlik om dit los van mekaar te bedink nie. Met blepeis hoti het die skrywer verduidelik wat hy bedoel en met die Skrifsitaat word die werke waardeur Abraham geregverdig is deur Isak te offer, gedefinieer in terme van geloof. Die gedagtelyn loop dus vanaf

uit die werke geregverdig (ex ergon edikaiothe) na .... geloof (pistis) (saamgewerk, sunergei) ..... met werke ..... uit die werke ..... die geloof (volkome geword eteilothe)

Geloof (episteusen) .....

Sunergei (saamgewerk) en eteilothe (volkome geword) dra nie die betekenis van geloof plus werke of werke plus geloof nie. Sunergei wil sê dat die een inherent met die ander saamgaan en eteilothe dat die een se bestaan deur die ander gekarakteriseer word. En so is ex ergon (uit die werke), hoewel dit in die begin alleen gebruik is, nie gedink sonder episteusen (hy het geglo) aan die einde nie. Die eenheid van geloof en werke word saamgevat met "hy is 'n vriend van God genoem." Dit definieer die model geloof en werke.

In die regverdigingsleer klop die hart van die werk van God in Christus vir die mens (indikatief). Jakobus stal dit op sy eie wyse uit en daag daardeur die gelowige uit om tenvolle te leef uit hierdie werk (imperatief) sodat hy "tot voile geestelike rypheid kan kom, volledig, sonder enige tekortkoming" (1:4). Hy gee op sy eie wyse verder deur wat Christus geleer het: "'n Goeie boom kan tog nie slegte vrugte dra nie, en 'n slegte boom nie goeie vrugte nie." (Matt 7:18).

\section{NOTAS}

1) Aangehaal uit L. Goppelt, Theologie des Neuen Testaments, Göttingen 1978.

2) G. Kittel, "Der Jakobusbrief und die apostolischen Väter", ZNW 43 (1950), $54 \mathrm{~V}$.

3) E. Baasland, "Der Jakobusbrief als Neutestamentliche Weisheitschrift," Studia Theologica 36 (1982), 119-139: "Innerhalb der protestantische Exegese hat man oft Jk 2, $14 f$ zum Mittelpunkt der Schrift gemacht. Aber dies hält kaum sicht." 